\title{
Sudden death in paediatrics as a traumatic experience for critical care nurses
}

\author{
Lígia Lima, Sandra Gonçalves and Cândida Pinto
}

\begin{abstract}
Background: Research shows that nurses working in critical care units and in particular, paediatric units, are at risk of developing symptoms of secondary traumatic stress (STS). However, little attention has been given to this phenomenon when associated with situations of sudden death in paediatrics.

Aim: This study aimed to examine the impact of sudden death in paediatrics on nurses working in paediatrics critical care units and to explore nurses' experiences of this event.

Methods: This study used a mixed-methods design. The Impact of Event Scale - Revised was used for investigating the presence of STS symptoms. In addition, an interview was conducted with six nurses.

Results: Fifty-seven percent of nurses responded to the surveys and six nurses were interviewed. The results showed that the sudden death of children and adolescents is an event that elicits symptoms of STS in nurses. The quantitative assessment, revealed that $19.4 \%$ presented total scores indicating high impact. The participants interviewed described experiences of subjective distress, such as intrusive thoughts, avoidance and hyperarousal. Other factors were also reported as influencing the experience of the sudden death of a child/adolescent, namely, the child's age, the cause of death and the family's reaction to the loss. According to the participants, the emotional impact was also determined by parenthood, previous training and professional experience.
\end{abstract}

Conclusions: Sudden death in paediatric critical care units is one of the most difficult situations in nursing practice and elicits STS symptoms, which may severely impact the physical and psychological health of nurses and ultimately affect the quality of the provided care.

Relevance for clinical practice: This study emphasizes the need for promoting better conditions for professional practice, namely, with regard to emotional support, as well as training programmes for skills development in the area of management of traumatic situations and of communication with clients.

Key words: Critical care $\bullet$ Emotional impact $\bullet$ Paediatric nursing $\bullet$ Secondary traumatic stress $\bullet$ Sudden death

\section{INTRODUCTION}

In paediatric critical care services, occurrences of sudden death are experienced by nurses as traumatic events, potentially affecting them physically and emotionally (Robins et al., 2009; Adriaenssens et al., 2012; Mason et al., 2014; Bloomer et al., 2015; Forster and Hafiz, 2015). The literature also stresses that within these types of situations, those reported as more difficult experiences are the ones related to sudden/unexpected death (Adriaenssens et al., 2012; Kellogg et al., 2014).

The unexpected death of a child is an event that causes severe stress and can trigger intense and negative emotional responses from the family (Garstang et al., 2014; Butler et al., 2015; Howes, 2015). This event can also affect the health professionals who provide care. Because nurses are frequently exposed to this type of event, they are most likely to develop emotional, behavioural or cognitive reactions reflecting their suffering, often expressed as secondary traumatic stress (STS) (Bloomer et al., 2015).

\section{BACKGROUND}

The first theoretical models explaining STS date back to the 1990s, following research conducted by Figley (1995, p. 10), who identified this phenomenon as the stress resulting from helping or wanting to help the traumatized or suffering person'. This suffering has also been conceptualized as compassion fatigue $(C F)$. Despite the existence of individual definitions for STS and $C F$, both terms are often used indistinctively (Sheen et al., 2014; Berger et al., 2015; Mangoulia et al., 2015), as STS is usually understood as clinical terminology whilst $C F$ is a more user-friendly expression to describe the experience (Sorenson et al., 2016).

STS has received considerable attention from several countries, and extensive research has been conducted involving nurses working in different areas and services, such as paediatric and neonatal critical care units (Bloomer et al., 2015), emergency services (Morrison and Joy, 2016), burn units (Kellogg et al., 2014) and psychiatric units (Mangoulia et al., 2015). However, there is still little evidence in the specific context of paediatrics. In these studies, although distinctive assessment instruments are used to analyse the presence of STS/CF, the prevalence of STS is quite often significant, ranging from 30\% to 50\% (Dominguez-Gomez and Rutledge, 2009; Mason et al., 2014; Berger et al., 2015

Authors: L Lima,PhD Psychology, CINTESIS Research Unit, Porto, Portugal. MSc Health Education and Health Promotion, BSc Psychology, Coordinator Professor, Escola Superior de Enfermagem do Porto (Nursing School of Porto), Porto, Portugal; S Gonçalves, Master's Degree in Child Health and Paediatrics, Registered Nurse, Hospital Dr. Nélio Mendonça, Avenida Luís de Camões, n 57-9004-514 Funchal, Portugal; C Pinto,PhD Psychology, MSc Health Psychology, Registered Nurse, 1 Coordinator Professor, Escola Superior de Enfermagem do Porto (Nursing School of Porto), Porto, Portugal

Address for correspondence: L Lima, Escola Superior de Enfermagem do Porto, Rua Dr. António Bernardino de Almeida, 4200-072 Porto, Portugal

E-mail: ligia@esenf.pt 
Mangoulia et al., 2015). The STS symptoms are similar to those usually described for post-traumatic stress disorder, although the affected individual does not experience the event directly, and as such, the impact of trauma on functionality is usually lower (Elwood et al., 2011). These impacts include the following: intrusion, which translates into fears, nightmares, and intrusive and uncontrollable thoughts and images from the traumatic event; avoidant behaviour, expressed as emotional numbness, apathy, and avoidance of people or locations related to the event; and hyperarousal, revealed through sleep pattern changes, difficulty in concentrating and mood changes (Figley, 1995; Mangoulia et al., 2015). Intrusion is considered the most significant dimension of this syndrome, as it leads the individual to uncontrolled invocations of the incident (Laposa et al., 2003).

Evidence shows that the occurrence of STS may be influenced by a set of circumstances, which can either reduce or exacerbate the emotional impact of this type of event. Literature suggests that, in general, women are more vulnerable to STS (Irish et al., 2011; Baum, 2016). In a study developed by Berger et al. (2015) involving paediatric nurses, age and professional experience were also identified as factors influencing $C F$. Inadequate institutional support and a lack of professional training were also noted as predictive factors for higher levels of $C F$ (Mason et al., 2014).

The importance of factors related to patients' personal characteristics, which may potentially influence the professionals' response to STS, are also discussed in the literature. These factors include the patients' age or cause of death (Berger et al., 2015). As an example, Bloomer et al. (2015) found that the patient's age was determinant, with nurses working in paediatric critical care units reporting higher levels of anxiety than those working in neonatal critical care units.

\section{OBJECTIVES}

This study aimed to investigate the impact of the sudden death of children/adolescents on nurses working in critical care units in Portugal and to explore their experiences of this type of traumatic event.

\section{METHODOLOGY}

A sequential mixed-methods design was used (Ivankova et al., 2006). Two questionnaires were first applied for the collection of quantitative data, and afterwards, an interview was conducted for the qualitative results. This triangulation of methods of data collection was chosen because the instrument used for investigating the emotional impact of paediatric death on nurses has not been used before for that purpose. As such, the qualitative data were meant to assist in explaining and interpreting the findings obtained.

\section{Participants}

A convenience sample of 62 nurses working in paediatric critical care services was obtained in two district hospitals, one located in Funchal and the other in Porto. These professionals were working in emergency services $(n=26 ; 42 \%)$ and intensive care services $(n=36: 58 \%)$. Nurses were considered eligible to participate if they had experienced at least one sudden death of a child/adolescent. Interviews were also conducted with a purposive sample of six nurses, with a balanced distribution of gender and age. Data saturation was used as a guiding criterion to establish the number of participants.

\section{Instruments}

- A questionnaire for socio-demographic and professional characteristics was used to evaluate variables such as age, gender, marital status, children and the number and chronology of sudden death in paediatrics experiences.

- The Impact of Event Scale - Revised (IES-R) scale, validated in Portuguese by Matos et al. (2011), is a self-report instrument that measures the impact of a specific event in terms of the degree of related subjective distress. As the scale assesses the presence of symptoms of intrusion, avoidance and hyperarousal, it is also adequate for the assessment of the impact caused by a traumatic event (Beck et al., 2008; Motlagh, 2010; Matos et al., 2011). The scale includes twenty-two items, eight of which correspond to the intrusion subscale, eight to the avoidance subscale, and six to the hyperarousal subscale. Each participant is asked to rate the impact according to a 5-point Likert scale ranging from 0 to 4 ('nothing', 'a little', 'moderately', 'much' and 'extremely', respectively).
A semi-structured interview was used for the qualitative approach. An interview guide was used that included four initiating questions, addressing the experience of the impact of sudden death in paediatrics: (a) Describe your personal experiences with the sudden death of children/adolescents; (b) Tell us about the impact that these events had on you; (c) Did any of these events had a higher impact? and (d) What were the circumstances surrounding that (those) event(s) that influenced the impact experienced? This guide was previously tested in two exploratory interviews with two nurses with characteristics similar to those of the nurses included in this sample.

\section{Procedure and ethical aspects}

Participants were asked by the lead nurse to fill in the questionnaire, and a drop box was left in each department. They were also asked if they were willing to be interviewed, and the first six who volunteered entered the study. The interviews were conducted in a private room at the hospital and each lasted approximately $30-45 \mathrm{~min}$. Ethical approval was granted by the research ethics committees of both hospitals. Participants freely agreed to participate in this study, and after being provided with all the information, they were given an informed consent form.

\section{Data analysis}

Quantitative data were analysed with Statistical Package for Social Scientists (SPSS) software (version 20., IBM Corp., Armonk, NY, USA). IES-R cut-off points were determined as suggested by Matos et al. (2011) to assess impact values translated into low, average and high impacts.

Qualitative data were audio recorded, transcribed verbatim and analysed using thematic analysis (Braun and Clarke, 2006). Initially, two researchers (S. G. and L. L.) analysed the interviews individually to highlight meaningful statements and generate the initial codes. Afterwards, the two researchers met to review their findings and discuss differences until a consensus was reached. The third phase consisted of aggregating codes into the themes, and these findings were shared among the research team, including the third researcher (C. P.), who reviewed the analysis. The last phase consisted of settling on and naming the final themes. 
Table 1 Descriptive statistics

\begin{tabular}{|c|c|c|c|}
\hline Variables & & & $n(\%)$ \\
\hline \multicolumn{4}{|l|}{ Gender } \\
\hline Male & & & $10(16 \cdot 1 \%)$ \\
\hline Female & & & $52(83.9 \%)$ \\
\hline \multicolumn{4}{|l|}{ Age (years) } \\
\hline $26-30$ & & & $14(22 \cdot 6 \%)$ \\
\hline $31-40$ & & & $34(54 \cdot 8 \%)$ \\
\hline $41-50$ & & & $12(19 \cdot 4 \%)$ \\
\hline$>51$ & & & $2(3 \cdot 2 \%)$ \\
\hline \multicolumn{4}{|l|}{ Marital status } \\
\hline Not married & & & $17(27 \cdot 4 \%)$ \\
\hline Married & & & $45(72 \cdot 6 \%)$ \\
\hline \multicolumn{4}{|l|}{ Children } \\
\hline No children & & & $29(46 \cdot 8 \%)$ \\
\hline With children & & & $33(53 \cdot 2 \%)$ \\
\hline \multicolumn{4}{|l|}{ No. of events } \\
\hline 1 & & & $7(11 \cdot 3 \%)$ \\
\hline $1-5$ & & & $21(33.9 \%)$ \\
\hline $5-10$ & & & $11(17 \cdot 7 \%)$ \\
\hline$>10$ & & & $23(37 \cdot 1 \%)$ \\
\hline \multicolumn{4}{|l|}{ Time frame } \\
\hline Last month & & & $1(1.6 \%)$ \\
\hline $1-5$ months & & & $17(27 \cdot 4 \%)$ \\
\hline 6 months to 1 year & & & $20(32 \cdot 3 \%)$ \\
\hline$>1$ year & & & $21(33.9 \%)$ \\
\hline Do not recall & & & $3(4 \cdot 8 \%)$ \\
\hline IES-R & Mean & SD & $\alpha$ \\
\hline Intrusion & $1 \cdot 35$ & 0.77 & 0.88 \\
\hline Avoidance & $1 \cdot 21$ & 0.68 & 0.81 \\
\hline Hyperarousal & 0.92 & 0.75 & 0.87 \\
\hline Total score - impact & $1 \cdot 18$ & 0.69 & 0.94 \\
\hline IES-R* & $\begin{array}{l}\text { Low } \\
\text { impact } \\
{[\%(n)]}\end{array}$ & $\begin{array}{c}\text { Average } \\
\text { impact } \\
{[\%(n)]}\end{array}$ & $\begin{array}{l}\text { High } \\
\text { impact } \\
{[\%(n)]}\end{array}$ \\
\hline Subscale intrusion & $17 \cdot 7(11)$ & $67 \cdot 7(42)$ & $14.5(9)$ \\
\hline Subscale avoidance & $16 \cdot 1(10)$ & $69 \cdot 4(43)$ & $14.5(9)$ \\
\hline Subscale hyperarousal & $19 \cdot 4(12)$ & $61 \cdot 3(38)$ & $19 \cdot 4(12)$ \\
\hline Total score - impact & $17 \cdot 7(11)$ & $62.9(39)$ & $19 \cdot 4(12)$ \\
\hline
\end{tabular}

IES-R, Impact of Event Scale - Revised

\section{RESULTS Quantitative study}

A total of 109 questionnaires were distributed in the two hospitals and 62 completed questionnaires were returned, giving a response rate of $57 \%$. The majority of the participants were female, with an average age of 35.7 years, most of whom were married and had children. When asked about the number of cases of sudden death that they had experienced and when they occurred, 50\% reported having had more than five experiences within a time frame of more than 6 months earlier (Table 1).
To describe the impact of the event 'sudden death of a child or adolescent' on nurses, the IES-R global score was calculated, as well as the scores for the intrusion, avoidance and hyperarousal subscales (Table 1). Low mean values were found, the highest being for intrusion.

The results show low impacts for the majority of respondents (Table 1). Nevertheless, $19.4 \%$ of participants presented total scores showing high impacts.

\section{Qualitative study}

Six nurses were interviewed (three from each institution). Their ages ranged between 32 and 53 years old, and five of them were female.

Two overall themes emerged during the examination of the transcribed interviews: emotional impact and circumstances affecting the emotional impact.

\section{Emotional impact}

Participants provided expressive narrative accounts of their experiences with sudden death in paediatrics, characterized by pervasive emotional distress that fit the symptoms of STS. The first, intrusion, has been described as the most important dimension of STS and involves uncontrolled, repetitive thoughts, which can be triggered through images, smells and other sensations and are a constant reminder of the event. The nurses reported various experiences indicative of intrusion, having used repeatedly the word 'ruminate', a term that describes the process of persistently thinking of something that involves suffering and distress. It was also mentioned that the sudden death of the child/adolescent causes enduring suffering:

\section{(...) I constantly ruminate over this, you know? And sometimes I take some time to ... I really ruminate over it until I get things straight. (E5P)}

Some behaviours described in the interviews expressed avoidance, namely, distancing from people or places associated with the event, apathy and emotional numbness. Additionally, the refusal to talk about the subject was also identified as an avoidant behaviour:

I cannot stay much longer in there like that ... everyone talking about the same thing and I do not... (pause) I do not like to talk about it ... Yes, I'd rather go

through this alone... (E5P)

The symptoms that fit into the dimension of hyperarousal were related to changes in sleep patterns and mood swings, difficulty in concentrating and physical symptoms such as headaches or migraines. Nurses reported changes in sleep patterns and difficulty in concentrating:

Then, I took it really bad ... I simply could not sleep ... (...) could not work properly, needed someone by my side. Every time I had to prepare medication, I'd check it with my colleague ... (E3P)

Confronting death situations often seems to promote an increased state of hypervigilance, as expressed by one of the interviewed nurses, who experienced three sudden deaths of children over a weekend and continued to experience physical symptoms throughout the interview:

(... ) it was a horrific weekend ... 3 deaths

in a row with small children... My

hands freeze just to talk about it ... (E2F)

\section{Circumstances influencing the emotional impact}

Several references were made to factors that were perceived as attenuating or exacerbating the emotional impact of sudden death in paediatrics. Some of these factors concerned circumstances related to the child/adolescent, others with the family of the child/adolescent, and others with the professional staff. Factors pertaining to professional training were also mentioned.

The factors associated with the child/adolescent were related to the patient's age and type/cause of death. The age of the child was one of the most important factors mentioned by nurses. These professionals reported that despite the intense suffering caused by the sudden death of a baby or small child, their deaths were not as devastating as the death of an adolescent or a preteen, as a life path had already established and family ties were already strong.

'(...) when babies are smaller (...) I don't feel so affected... The same for parents, the more grown-up the children, the more parents get attached ...' (E5P) 


\section{An adolescent already has a life project (...) $(E 4 P)$}

Nurses highlighted the unpredictability of death as one the factors inducing more suffering and conveyed a particularly traumatic burden associated with this situation, namely, when it results from an accident:

\section{(...) Traumatic brain injury ... that feel- ing when you wake up and everything is okay, children go to school and they don't come back home. (...) The disease... I think people are much more prepared. With sudden death, not really ... (E5P)}

In relation to the family's reaction to the death of the child/adolescent, and in particular, the parents' reactions, nurses reported being extremely affected by the shock and intense suffering they witnessed:

\section{(...) the lady at the door saying "my son is dead inside the car", I'll never forget that image ... (E3P)}

In terms of what concerns the health professional, several factors were mentioned that conditioned the impact of the sudden death of the child/adolescent, particularly the nurses' professional experience, which was identified as a protective factor and which provided these professionals with more effective coping mechanisms:

I think that we, the oldest, are more capable of overcoming this, and, in a way, we resign ourselves to that fact and try... we easily forget. It's more difficult for the youngest (E3P)

On the other hand, the nurses' personal experiences of motherhood/fatherhood were mentioned as potentiating their own suffering:

(...) and then: we have children and we begin to wonder... this could have happened to my child, couldn't it? (E3P)

Nurses' experiences of motherhood/fatherhood increased their feelings of closeness to the families, particularly to parents. These bonding ties often exacerbated the impact, especially in cases in which the age and gender of the child/adolescent

were similar to those of the nurses' children, or in cases in which the context of the event reminded nurses of some personal experience:

\section{I clearly remember a child coming into the unit who was just like my son. And I panicked ... (E5P)}

As for the factors related with professional training, the nurses mentioned difficulties in giving bad news. They referred to these situations as being one of the most difficult and stressful tasks, as illustrated in the following quote:

\section{(...) I find it most hard to give the bad news, not going through the situation ... (E2F)}

With regard to the communication process, finding the right words with which to give the news to the family was also considered particularly difficult, and the word 'death' was often indicated as a term to avoid:

\section{(...) some people don't fear the word death and this might be important, I don't know ... How do we explain the situation to the parents? We just say, your child is dead? We couldn't do anything? What's best for the parents? ... (...) how do we say it to them? (E4P)}

Some nurses associated the negative impact of the sudden death of a child/adolescent to a lack of training and institutional support necessary to address this type of situation, stressing the need for continuous training in this field:

(...) this happens quite often, it happened to me and it still does, because I'm not sure what it is, what should I do ... because... Well, because we're not fully trained (...) (E4P)

(...) We don't have psychological support, we have nothing. It is up to you to cope with the situation your own way ... zero support! ( ...) (E2F)

\section{DISCUSSION}

This study aimed to study the impact of the sudden death of children and adolescents on nursing professionals working in paediatric critical care units. The quantitative component of the study revealed that approximately $20 \%$ of the nurses showed high levels of impact, indicative of the presence of STS symptoms. These scores are lower than those found in previous studies, which showed STS/CF values ranging between $30 \%$ and 50\% (Dominguez-Gomez and Rutledge, 2009; Mason et al., 2014; Berger et al., 2015; Mangoulia et al., 2015). However, the results cannot be compared directly, as the assessment tools used varied across the different studies. In addition, in the interpretation of this study results, it is important to consider the time that elapsed between the experience of the events and the data collection. Some of the death-related situations under consideration were so distant in time that its impact may have been softened through the cognitive processes (even evocation) and emotional processes involved in coping mechanisms.

In relation to the scores obtained from the IES-R, the highest score found was for the intrusion subscale, similar to findings from a previous study (Heeb et al., 2011). Thus, we can infer that for nurses working in paediatric critical care units, STS is mostly expressed through symptoms of intrusion. The hyperarousal subscale showed the lowest average scores, and it should be noted that scores for the mean and standard deviation were very close, indicating little dispersion in the answers. From the revised studies, none has presented similar scores. These two results (low score and considerable homogeneity) might indicate that although participants were able to recognize symptoms described in the items related to hyperarousal, overall, they did not seem to identify themselves with these items.

Interestingly, and despite the fact that the quantitative data analysis indicated that the majority of the nurses showed impact values within the normal range, which were not indicative of STS, when qualitative data were collected through interviews, findings showed that the event under study caused significant distress in all participants. The reports clearly illustrate the dimensions of STS, including symptoms of intrusion, which were expressed in recalls of the event as being involuntary and recurrent, in addition to inducing discomfort. The word 'ruminate' seemed to describe this process, and it should be noted 
that it was used by more than one participant. Experiences that fit into avoidance symptoms were also described, with silence being the most frequently mentioned. In this particular situation, one can infer that avoidant behaviours, such as not talking about the subject or not showing negative feelings, were the most commonly accepted strategies within teams. They neither disclosed the individual's weaknesses nor put additional pressure on colleagues, thus increasing the burden on individual team members of having to address the problems on their own.

Persistent physiological activation and arousal symptoms were equally described, expressed as sleep problems. Dominguez-Gomez and Rutledge (2009) argue that change in sleep patterns is mostly described by nurses in the emergency room, and these symptoms were also reported by the nurses interviewed in this study.

It was also found that some of the factors described in the literature as being associated with the impact of the sudden death of children and adolescents may have conditioned the extent and nature of distress related to the experience, according to the respondents. Thus, the age of the child seemed to mediate the experienced suffering, which increased as the child grew older, as Bloomer et al. (2015) also acknowledge. The awareness of children/adolescents of life and its finitude increased the likelihood of negative feelings among nurses. In fact, the distinction made by nurses regarding the age of the children/adolescents can be based on findings related to child development, because the concept of death as something immutable and definite is only perceived by the child at approximately 10 years of age. This phenomenon explains the extent of the suffering caused by the death of an adolescent, as this individual is already aware of the personal and social implications of death (Healy and Tyrrell, 2011). Moreover, the family's emotional reaction to death is very likely to perpetuate in the memories of nursing professionals, as previous research has demonstrated (Garstang et al., 2014; Howes, 2015).

As described in the literature, the emotional impact experienced by the nurses still depends on their professional experience (Berger et al., 2015) and, as suggested in this study, from life experience itself, and in particular, when nurses are also parents themselves. The situations in which nurses perceived some physical or emotional similarities with their own children were particularly difficult and led these professionals to identify more with the patient's family. Somehow, in these situations, they projected themselves onto the experience, causing intense suffering. Nurses also reported increased suffering when experiencing physical or emotional closeness to children who somehow resembled their own children.

Additionally, nurses must cope with the difficult process of communicating with both the family and the team when the death of a child/adolescent occurs. People often avoid using the word death, with some authors referring to it as a taboo subject (Healy and Tyrrell, 2011). Communication is a complex process, and each family is unique and has a particular way of going through this experience, rendering this process even more difficult. Notwithstanding, using simple, non-metaphorical and objective language when communicating with parents is extremely important, so that no false expectations are raised (Levetown, 2004).

Importantly, nurses also argued that they felt a lack of education and professional training in terms of how to address these situations. Similar results were found in a qualitative study conducted with nurses who experienced the death of paediatric patients in a burn unit, and one of the themes that emerged from the analysis of their interviews was the feeling of a lack of training to address this type of situation (Kellogg et al., 2014). The literature also emphasizes that nurses need training to be capable to confront their patients' deaths (Knapp and Mulligan-Smith, 2005; Forster and Hafiz, 2015).

\section{STUDY LIMITATIONS}

Some limitations of the study should be mentioned. Due to the small sample size and the fact that participants were recruited only from two hospitals, caution must be applied, as the findings might not be transferable to all nurses working in paediatric critical care services. Notwithstanding, the triangulation of methods enabled a deeper comprehensiveness of the subject under study.

\section{CONCLUSION}

Nurses working in paediatric critical care units are frequently exposed to traumatic events, including the unexpected and sudden death of children and adolescents. This study aimed to understand and describe the emotional impact of this type of traumatic event on nurses.

The findings from this study suggest that the sudden death in paediatrics causes significant suffering for nurses. Some circumstances seem to influence the impact of this event, namely, factors related to the child/adolescent, their families and professionals. The lack of training and institutional support was also emphasized by nurses. Nonetheless, these aspects were considered by the professionals interviewed as extremely important for the process of coping with the sudden death of a child/adolescent.

An important implication of this study for future clinical practice is the need to address this phenomenon and develop interventions with the nursing staff that will help nurses to cope with the sudden death of paediatric patients, preventing symptoms of STS. Some activities may be developed autonomously by the nursing team, such as meetings, in which sharing experiences and expressing feelings are encouraged. Other activities may be developed outside the professional context at a social level, which may involve leisure activities used to encourage the establishment of informal supportive social networks among professionals. Further work needs to be carried out on education and continuous training as ways to provide the best possible care for these professionals. In addition, future research could contribute more knowledge in this area.

\section{ACKNOWLEDGEMENTS}

This article was supported by FEDER through the operation POCI-01-0145-FEDER-007746 funded by the Programa Operacional Competitividade e Internacionalização - COMPETE2020 and by National Funds through FCT - Fundação para a Ciência e a Tecnologia within CINTESIS, R\&D Unit (reference UID/IC/4255/2013). 


\section{WHAT IS KNOWN ABOUT THIS TOPIC}

- Experiences of the sudden death of a child/adolescent are distressing for the health care team, potentially affecting the health of these professionals.

\section{WHAT THIS PAPER ADDS}

- The confrontation with situations of sudden death in paediatric services can trigger symptoms of post-traumatic stress in nursing professionals.

- The use of a mixed methodology for the analysis of this STS provides a more comprehensive approach to this phenomenon.

- The management of the impact of the death of a child among nursing professionals appears to be mediated by several factors, namely, the child's age, the cause of death and the family's reaction to the loss.

- The emotional impact is also influenced by previous training and professional experience.

\section{REFERENCES}

Adriaenssens J, de Gucht V, Maes S. (2012). The impact of traumatic events on emergency room nurses: findings from a questionnaire survey. International Journal of Nursing Studies; 49: 1411-1422.

Baum N. (2016). Secondary traumatization in mental health professionals: a systematic review of gender findings. Trauma Violence Abuse; 17: 221-235.

Beck JG, Grant DM, Read JP, Clapp JD, Coffey SF, Miller LM, Palyo SA. (2008). The impact of event scale-revised: psychometric properties in a sample of motor vehicle accident survivors. Journal of Anxiety Disorders; 22: 187-198.

Berger J, Polivka B, Smoot EA, Owens H. (2015). Compassion fatigue in pediatric nurses. Journal of Pediatric Nursing; 30: e11-e17.

Bloomer MJ, O'Connor M, Copnell B, Endacott R. (2015). Nursing care for the families of the dying child/infant in paediatric and neonatal ICU: nurses' emotional talk and sources of discomfort. A mixed methods study. Australian Critical Care; 28: 87-92.

Braun V, Clarke V. (2006). Using thematic analysis in psychology. Qualitative Research in Psychology; 3: 77-101.

Butler A, Willetts G, Copnell B. (2015). Nurses' perceptions of working with families in the paediatric intensive care unit. Nursing in Critical Care; 22: 195-202.

Dominguez-Gomez E, Rutledge DN. (2009). Prevalence of secondary traumatic stress among emergency nurses. Journal of Emergency Nursing; 35: 199-204.

Elwood LS, Mott J, Lohr JM, Galovski TE. (2011). Secondary trauma symptoms in clinicians: a critical review of the construct, specificity, and implications for trauma-focused treatment. Clinical Psychology Review; 31: 25-36.

Figley CR. (1995). Compassion fatigue as secondary traumatic stress disorder: an overview. In: Figley CR, (ed), Comparission Fatigue: Coping with Secondary Traumatic
Stress in those Who Treat the Traumatized. New York: Brunner-Routledge.

Forster E, Hafiz A. (2015). Paediatric death and dying: exploring coping strategies of health professionals and perceptions of support provision. International Journal of Palliative Nursing; 21: 294-301.

Garstang J, Griffiths F, Sidebotham P. (2014). What do bereaved parents want from professionals after the sudden death of their child: a systematic review of the literature. BMC Pediatrics; 14: 269.

Healy S, Tyrrell M. (2011). Stress in emergency departments: experiences of nurses and doctors. Emergency Nurse; 19: 31-37.

Heeb J-L, Gutjahr E, Gulfi A, Dransart DAC. (2011). Psychometric properties of the French version of the impact of event scale-revised in mental health and social professionals after a patient suicide. Swiss Journal of Psychology; 70: 105-111.

Howes C. (2015). Caring until the end: a systematic literature review exploring paediatric intensive care unit end-of-life care. Nursing in Critical Care; 20: 41-51.

Irish LA, Fischer B, Fallon W, Spoonster E, Sledjeski EM, Delahanty DL. (2011). Gender differences in PTSD symptoms: an exploration of peritraumatic mechanisms. Journal of Anxiety Disorders; 25: 209-216.

Ivankova NV, Creswell JW, Stick SL. (2006). Using mixed-methods sequential explanatory design: from theory to practice. Field Methods; 18: 3-20.

Kellogg MB, Barker M, McCune N. (2014). The lived experience of pediatric burn nurses following patient death. Pediatric Nursing; 40: 297-301.

Knapp J, Mulligan-Smith D. (2005). Death of a child in the emergency department. Pediatrics; 115: 1432-1437.

Laposa JM, Alden LE, Fullerton LM. (2003). Work stress and posttraumatic stress disorder in ED nurses/personnel. Journal of Emergency Nursing; 29: 23-28.
Levetown M. (2004). Breaking bad news in the emergency department: when seconds count. Advanced Emergency Nursing Journal; 26: 35-43.

Mangoulia P, Koukia E, Alevizopoulos G, Fildissis G, Katostaras T. (2015). Prevalence of secondary traumatic stress among psychiatric nurses in Greece. Archives of Psychiatric Nursing; 29: 333-338.

Mason VM, Leslie G, Clark K, Lyons P, Walke E, Butler C, Griffin M. (2014). Compassion fatigue, moral distress, and work engagement in surgical intensive care unit trauma nurses: a pilot study. Dimension in Critical Care Nursing; 33: 215-225.

Matos M, Pinto-Gouveia J, Martins S. (2011). O impacto traumático das experiências de vergonha: estudo das propriedades psicométricas da versão portuguesa da Impact of Event Scale - Revised. Psychologica; 54: 413-438.

Morrison LE, Joy JP. (2016). Secondary traumatic stress in the emergency department. Journal of Advanced Nursing; 72: 2894-2906.

Motlagh H. (2010). Impact of event scale-revised. Journal of Physiotherapy; 56: 203-203.

Robins PM, Meltzer L, Zelikovsky N. (2009). The experience of secondary traumatic stress upon care providers working within a children's hospital. Journal of Pediatric Nursing; 24: 270-279.

Sheen K, Slade P, Spiby H. (2014). An integrative review of the impact of indirect trauma exposure in health professionals and potential issues of salience for midwives. Journal of Advanced Nursing; 70: 729-743.

Sorenson C, Bolick B, Wright K, Hamilton R. (2016). Understanding compassion fatigue in healthcare providers: a review of current literature. Journal of Nursing Scholarship: An Official Publication of Sigma Theta Tau International Honor Society of Nursing; 48: 456-465. 